\title{
Action Research on Motivation in English Reading
}

\author{
Qian Huang \\ Foreign Language Teaching Department, Dezhou University, Dezhou 253023, China \\ Email: qqh@dzu.edu.cn
}

\begin{abstract}
The study of motivation has been a long time and has developed into a range of theories in which varieties of factor are involved in. By introducing the definition of motivation, and its classification and analyzing the function of motivation in language learning, this paper is attempt to survey some strategies and methods about how to motivate and train learning motivation in English reading class. The data reveals that Female learners have strong motivation in intrinsic, extrinsic and importance of reading. But in reading efficacy, male learners are stronger than female learners. The result also indicates that students with higher score have strong motivation in learning English reading than students with lower score.
\end{abstract}

Index Terms — reading, motivation theories, questionnaire, motivational strategies

\section{INTRODUCTION}

It is almost universally believed that a successfully language learner has usually highly motivated. The study of motivation has been a long time and has developed into a range of theories in which varieties of factor are involved in. However, this study intends to investigate what affects students' learning motivation and attitudes in English reading class. Research on reading motivation has focused upon several attributes of motivation. The dimensions of motivation have been examined in relation to why students choose to engage or not in reading because of competency and efficacy beliefs, intrinsic and extrinsic motivation, and reasons for achievement which direct their motivation toward reading (Baker \& Wigfield, 1999).

Reading has gradually been getting popularity as one of the most effective strategies for motivating second language learners at various proficiency levels. Many experts have emphasized the importance of setting reading in foreign language curricula (Krashen, 1982), and a lot of studies have shown the effectiveness of reading in contexts of English or other languages as a second language and as a foreign language. These experts have asserted that reading plays an important role in developing fluent L2 readers because learners develop the ability to rapidly read large quantities of written material without using dictionaries. According to Smith, learners can learn to read by reading. Some studies also indicate that reading can favorably affect students' motivation and attitudes toward reading in an L2.

\section{Motivation}

\section{A. Definition of Motivation}

The term 'motivation' presents a real mystery: people use it widely in a variety of everyday and professional contexts without the slightest hint of there being a problem with its meaning, and most of us would agree that it denotes something of high importance. In general sense, motivation can be defined as the dynamically changing cumulative arousal in a person that initiates, directs, coordinates, amplifies, terminates, and evaluates the cognitive and motor processes whereby initial wishes and desires are selected, prioritized, operationalised and successfully or unsuccessfully acted out (Dornyei and Otto, 1998). Motivation is a theoretical construct used to explain the initiation, direction, intensity, persistence, and quality of behavior, especially goal-directed behavior.

Motives are usually construed as relatively general needs or desires that energize people to initiate purposeful action sequences. In contrast, goals and related strategies tend to be more specific and to be used to explain the direction and quality of action sequences in particular situations. In the classroom context, the concept of student motivation is used to explain the degree to which students invest attention and effort in various pursuits, which may or may not be the ones desired by their teachers. Students' motivation is rooted in students' subjective experiences, especially those connected to their willingness to engage in lessons and learning activities and their reasons for doing so.

\section{B. The Classification of Motivation}

Many of the current theories of second language motivation come from the early work of Gardner and Lambert. They are the first to make a distinction between integrative motivation and instrumental motivation and this has a tremendous influence on virtually all second language related research in this area. However, different researchers have different opinions, because they are standing on different angles, they give motivation different classification. Other researchers such as Krashen, Giles and Brynes, Clement, and Allard and Landry have attacked the problem from different 


\section{perspectives.}

\section{Intrinsic and Extrinsic Motivation}

Intrinsic motivation is usually defined as motivation which is guided by an interest in the task itself in which one is engaged, it means the motivation to learn the language derives from an inner desire and competence, whereas extrinsic motivation is for the sake of extrinsic rewards, such as parental or teacher's approval, offer of a reward, prizes, threat of punishment, a good grade, etc.

The distinction is more useful for teachers. Intrinsic motivation refers to the urge to engage in the learning activity for its own sake and extrinsic motivation is derived from external incentives. Penny Ur stated that both of the motivations have an important part to play in classroom motivation, and both are at least partially accessible to teacher influence.

Therefore, intrinsic motivation comer from one's inner parts whereas extrinsic motivation results from outer factors such as social situations, cultural influence, as well as families and educational conditions. For instance, compliments from parents and encouragement from teachers are sometimes the vital factors to a student. Crookes and Schmidt's suggestion is especially useful in three ways. 1) Reading materials should be moderately challenging, neither too difficult nor too easy. 2) Group work is more important than teachers' need mono-lecture. 3) The teacher should in the first place take learners' need into consideration.

In spite of the fact that different researchers come to different conclusions concerning the definition and the division of motivation, one thing is possibly certain, most researchers agree that motivated learners will achieve more than less motivated ones.

\section{Reading and Motivation}

Before turning to the "what" of reading, however, I would like to comment briefly on the even more fundamental question - from the teacher's point of view, at least — of why people choose, or don't choose, to read. For any approach to teaching to succeed, no matter how true to the latest "scientific principles," it must take into account the real needs and desires of learners - that rather loosely defined cluster of goals, inclinations, and biases which we call "motivation" - and we must therefore give some thought to what motivates people to read, or not to read, anything. In the real world — as opposed to the academic world — people who read, read for intellectual profit or pleasure. That is, they believe that the content of whatever they have chosen to read will be useful to them, or will help them to understand the world better, or will give them the special kind of pleasure that comes from the experience of reading literature. For students, of course, there are constraints, called"assignments," on this freedom of choice, but even a secondary, academic goal like "passing the course" provides something like a real-world motivation for reading. Very few students read just to practice their reading, or to build up their general knowledge of a language — both objectives worth pursuing but an ongoing reading experiences. Teachers take the role of active participant and model reader, lending prestige, example, and support to the activity. The individual, private nature of reading also makes it easier for teachers to establish a non-competitive, non-judgemental community of readers. Fear of evaluation by teacher and peers is minimized because the emphasis is not on a right answer, but on students' personal reactions to the reading material. The individual variation inherent in any teaching and learning situation can also be provided to, for a reading approach does not deal with students in a lockstep manner in which all learners have to read the same material at approximately the same rate.

\section{QUESTIONNAIRE OF READING MOTIVATION}

\section{A. Instrument and Subjects}

The questionnaire was adapted from Gardner's Attitude/Motivation Test Battery (AMTB), which included 39 statements on motivation concerning intrinsic motivation, extrinsic motivation, importance of reading and reading efficacy. The questionnaire was designed according to the Likert five-point rating scale assessing participants' attitudes on motivation. Each question has five choices ranging from "strongly disagree' to "strongly agree" which is represented in the number from 1 to 5. Likert's measurement table is applied in order to give subjects a chance to be in the middle point of the balance. The subjects were told that there is no "right" or "wrong" answer to the questions and were asked to choose the answer which was most appropriate to his or her opinions.

The subjects for the study were 156 non-English major undergraduates who are randomly chosen from grade two in a certain university in Northwest. Among which there are 129 female subjects (occupies 83\%) while 27 subjects are male (occupies17\%). They had English reading classes both intensive and extensive and have mostly got rid of the influence of the previous education like junior and senior high school and are accustomed to the college curriculum. They have been studying English for at least 8 years and have formed a set of relatively fixed learning patterns, especially in English reading. For the fact that the subjects use the same version of English reading course-books and have the same teaching hours each week, so, theoretically, the subjects' English reading levels are nearly the same.

\section{B. Procedures}

The investigation could be roughly divided into three periods. The first period could be called pre-investigation period, since the writer did a lot of interviews beforehand in order to make the questionnaire suitable to the subjects' 
case. In the second period, the questionnaire was done separately concerning L2 learners' general motivation in reading. The last period was mainly on statistical collection and tests results analyses.

\section{DATAANALYSIS}

\section{A. Introduction}

The data analysis was performed with SPSS 11.0 of two parts. First, a factor analysis was conducted to explore motivation types. Second, MANOVA was carried out to examine whether these features had significant effects on various types of motivation in English reading. For better illustration and easier statistical description of the data, the result of the investigation of English learners' general motivation in reading will be shown in the following tables.

In this chapter, the writer is going to study motivation in reading among foreign language learners as non-English majors. First of all, an investigation will be carried out to look into the students' general motivation in reading. That is to see whether they have strong or weak motivation in English reading. Another investigation will be concerned with students' motivation orientation. The purpose is to find out whether students' are more instrumental oriented or more enjoy oriented. This investigation also reveals the subjects' general motivation from a different aspect. The investigation over students' reading proficiency may reveal some connection between students' reading motivation and their performance in reading comprehension tests.

B. Data Collection and Analysis

TABLE 4.1

DESCRIPTIVE STATISTICS OF THE AVERAGE MEANS OF MOtIVATION QUESTIONS

\begin{tabular}{|c|c|c|c|c|c|c|c|c|c|c|}
\hline & Q1 & Q2 & Q3 & Q4 & Q5 & Q6 & Q7 & Q8 & Q9 & Q10 \\
\hline Means & 3.20 & 4.50 & 2.77 & 2.35 & 4.03 & 2.77 & 2.20 & 4.15 & 3.72 & 2.33 \\
\hline & Q11 & Q12 & Q13 & Q14 & Q15 & Q16 & Q17 & Q18 & Q19 & Q20 \\
\hline Means & 3.41 & 3.92 & 3.11 & 3.58 & 3.67 & 3.72 & 2.91 & 2.00 & 2.31 & 2.18 \\
\hline & Q21 & Q22 & Q23 & Q24 & Q25 & Q26 & Q27 & Q28 & Q29 & Q30 \\
\hline Means & 3.10 & 2.39 & 2.31 & 2.70 & 3.19 & 3.75 & 3.72 & 4.28 & 4.19 & 4.10 \\
\hline & Q31 & Q32 & Q33 & Q34 & Q35 & Q36 & Q37 & Q38 & Q39 & Q40 \\
\hline Means & 4.19 & 4.24 & 2.97 & 2.10 & 2.89 & 3.36 & 3.20 & 3.03 & 2.85 & 2.60 \\
\hline
\end{tabular}

Table 4.1 shows the descriptive statistics of the average means of the total 39 questions. The subjects are asked to answer 39 statements concerning four categories related to intrinsic motivation, extrinsic Motivation, and importance of reading and reading efficacy.

TABLE 5.2

DESCRIPTIVE Statistics of THE AVERAgE MEAns OF Motivation Questions

\begin{tabular}{|c|c|c|c|c|r|}
\hline 36Motivation & Number & Minimum & Maximum & Mean & \multicolumn{1}{c|}{ Std. Deviation } \\
\hline intrinsic & 20 & 2.00 & 4.50 & 3.1415 & .75726 \\
\hline extrinsic & 9 & 2.31 & 4.28 & 3.2922 & .73749 \\
\hline importance & 5 & 2.10 & 4.24 & 3.5200 & .95166 \\
\hline efficacy & 6 & 2.60 & 3.36 & 2.9883 & .26992 \\
\hline
\end{tabular}

Table 4.2 shows the descriptive statistics of the average means of the total 39 questions. The subjects are asked to answer 39 statements concerning four categories related to intrinsic motivation, extrinsic motivation, and importance of reading and reading efficacy.

TABLE 4.3

SHOWS THE DESCRIPTIVE STATISTICS OF LEARNERS' GENERAL MOTIVATION IN READING

\begin{tabular}{|c|c|c|c|c|r|}
\hline 36Motivation & Number & Minimum & Maximum & Mean & \multicolumn{1}{|c|}{ Std. Deviation } \\
\hline intrinsic & 20 & 2.00 & 4.50 & 3.1415 & .75726 \\
\hline extrinsic & 9 & 2.31 & 4.28 & 3.2922 & .73749 \\
\hline importance & 5 & 2.10 & 4.24 & 3.5200 & .95166 \\
\hline efficacy & 6 & 2.60 & 3.36 & 2.9883 & .26992 \\
\hline
\end{tabular}


It reveals that there are some differences among the four categories of motivation in this study. The mean of importance of reading (mean $=3.5200$ ) is higher than the other three categories (intrinsic mean $=3.1415$; extrinsic mean $=3.2922$; efficacy mean $=2.9883$ ). And the differences are significant. That is to say, most students think reading is very important in learning a foreign language. This result is likely to represent the importance of learning to read in English as an international language. From this table, it is obvious that the differences of stand deviation among the four categories are also significant. The standard deviation of reading efficacy (.26992) is much lower than intrinsic (.75726), extrinsic (.73749) and importance of reading (.95166). This result shows that most subjects put reading efficacy in a very important position in English learning.

TABLE 4.4

MOTIVATIONAL DIFFERENCES BETWEEN MALE AND FEMALE LEARNERS

\begin{tabular}{|c|c|c|c|c|}
\hline \multirow{4}{*}{ Motivation } & Gender & Mean & Std. Deviation & Number \\
\hline \multirow{4}{*}{ intrinsic } & female & 3.1616 & .24283 & 129 \\
\cline { 2 - 5 } & male & 3.0500 & .30224 & 27 \\
\cline { 2 - 5 } & total & 3.1423 & .25654 & 156 \\
\hline \multirow{3}{*}{ extrinsic } & female & 3.2997 & .37925 & 129 \\
\cline { 2 - 5 } & male & 3.2510 & .39025 & 27 \\
\cline { 2 - 5 } & total & 3.2913 & .38039 & 156 \\
\hline \multirow{3}{*}{ importance } & female & 3.5225 & .27985 & 129 \\
\cline { 2 - 5 } & male & 3.5158 & .37317 & 27 \\
\cline { 2 - 5 } & total & 3.5218 & .29671 & 156 \\
\hline \multirow{7}{*}{} & female & 2.9765 & .49849 & 129 \\
\cline { 2 - 5 } & & & & \\
\hline
\end{tabular}

Table4.4 shows the motivational differences between male and female learners. It reveals that there are some significant differences between male students and female students. From table 6, we can see female students' mean is higher than male students in terms of intrinsic motivation, extrinsic motivation and importance of reading, while male students' efficacy mean is high than female (male $=3.0617$, female $=2.9765$ ). And the standard deviation is the same. That is to say, female learners have strong motivation in intrinsic, extrinsic and importance of reading. But in reading efficacy, male learners are stronger than female learners.

TABLE 4.5

TESTS OF BETWEEN-SUBJECTS EFFECTS

\begin{tabular}{|l|l|l|l|l|l|}
\hline \multicolumn{1}{|c|}{ Source } & \multicolumn{1}{c|}{ Type III Sum of Squares } & df & Mean Square & F & Sig. \\
\hline Corrected Model & 23.965 & 4 & 5.991 & 440446 & .000 \\
\hline Intercept & 3727.463 & 1 & 3727.436 & 27652.253 & .000 \\
\hline Motivation & 23.930 & 3 & 7.977 & 59.175 & .000 \\
\hline Gender & $3.494 \mathrm{E}-02$ & 1 & $3.494 \mathrm{E}-02$ & .259 & .611 \\
\hline Error & 83.439 & 619 & .135 & & \\
\hline Total & 6644.473 & 624 & & & \\
\hline Corrected Total & 107.404 & 623 & & & \\
\hline
\end{tabular}

Table 5.4 shows the Tests of Between-Subjects Effects related to gender. From this table, we can see that the degree of freedom (df) of motivation is 3 , the value of $\mathrm{F}$ is $59.175(\mathrm{p}<0.05)$. And the degree of freedom (df) of gender is 1 , the value of $F$ is .259 ( $\mathrm{p}>0.05)$.

Besides questionnaire also shows both students in higher score group and lower score group think English reading is very important in learning a foreign language. The influence of extrinsic motivation lies in the second position for both groups, and then comes intrinsic motivation. Both the two groups regard that reading efficacy has little influence on their motivation in English reading. For each of the four factors, students from the higher score group are much stronger than students from the lower score group. This indicates that students with higher score have strong motivation in learning English reading than students with lower score. So it is clear that the results of students' reading tests will be greatly influenced by their leaning motivation.

\section{MAJOR FINDINGS AND IMPLICATIONS}




\section{A. Major Findings}

As a dynamic process, motivation is one of the most important aspects of affecting foreign language learning, and it is also one of the most initiative factors and a complex area involving many interrelated factors. If one has high motivation, especially integrative and intrinsic motivation, he or she has more chances to succeed in learning. After a series of statistical analyses of the correlation between the reading proficiency and the motivation, conclusions are reached here:

1. The majority of the English students have a strong motivation towards English reading;

2. Female students show a stronger intrinsic and extrinsic motivation than male students, which indicates that gender is a very important variable in English learning;

3. The correlation between general motivation and reading is significant;

4. The correlation between students with higher score and lower score is significant.

Therefore, in foreign language teaching, firstly, language teachers should motivate and train integrative and intrinsic motivation. To those learners who are lacking in motivation, teachers could not hurry too much. Teachers should give them initiative feedback for their endeavor and stimulate their extrinsic motivation in order to let them enjoy learning. And teachers should become familiar with the motivation theories and the valuable contributions of different theorists as well as the implications of these theories in English language teaching. In the process of this stage, their intrinsic motivation can be stimulated and improved. Secondly, it is advisable that teachers know the motivational factors, learners' attitudes towards English learning, their learning motivation and success or failure attributions. Thirdly, it is important for the teachers to search for the teaching strategies to create a supportive and relaxing learning environment, initiate students' motivation to learn, enhance and maintain their motivation, and make positive attribution and evaluation in language learning. Once learners have strong learning motivation, they would put their potentials into practice as possible as they can, the learning efficiency will be naturally improved at high speed.

\section{B. Approaches to Train Students' Motivation in Reading}

From most linguists' point of view, the important thing is not how much that learners should be taught, but that learners should be given the motivation to learn. Many successful teaching depends upon learners' learning strategies. There is no point in providing entertaining, lively, well-constructed language lessons if students do not have the motivation to learn. So motivation is regarded as one of the most important factors in influencing learners' learning efficiency and it has been proved to have great educational significance. In China, a real fact is that English is a foreign language and many students lack natural acquisition environment. Teachers' role is quite important for learning activities that mainly happen in the classroom. Experienced English teachers concern themselves with motivation and one of the persistent challenges for them is how to motivate the unmotivated learners and help reduce their negative attitudes toward English learning.

The above mentioned study has proved that students' motivational level is strongly influenced by learners' attitude and many motivational factors. These factors function together to influence learners' motivational behavior. Learners with different features in these attitudes and motivational variables have different motivational behavior. Related to the findings of the study, the key of motivating students to learn lies in enhancing their motivational level through changing their psychological states and cognitive orientations relevant to motivation.

1. Create a harmonious and natural teaching environment

Though students' attitudes to language learning and teaching materials are relatively stable, some of them are prone to be influenced by their teachers and learning environment. Their attitudes towards the learning situations as measured by feelings about the classroom teachers and level of anxiety about the classroom atmosphere contribute to their motivational level. So the factors of teachers and input environment deserve our attention. Some specific proposals are as follows:

2. Improve the comprehensive qualities of teachers

According to the above research result, there are significant motivational differences between those who think highly of their teachers and those who do not. So teachers must:

3. Set themselves as good examples that have not only specialized knowledge and generalized multiple skills but moral integrity as well for students. They should make efforts to establish friendly and harmonious relationship with students.

4. Have professionally appropriate level of knowledge and some awareness soft he appropriate means for carrying out needed analyses related to language, language variations, the students, and the goals and contexts of language instruction. With such awareness and professional skills, teachers are better equipped to make students become aware of significant features and patterns; plan and implement language instruction which promotes a variety of participation opportunities for practicing the language; control the learners' intensity of exposure and instruction in reading; ensure them to receive feedback about their performance and multiple possibilities for success.

5. Effective teaching and classroom management are inseparable. Teachers should be not only perfect in English but also good at managing the class. What they say and do in the instructional setting must aim at creating the conditions conductive for learning to occur. Exemplary teachers seek to arrange learning experiences in a way that each student experiences success for demonstrated progress and receives positive reinforcement for achievement. Teachers should 
perform as seriously or sympathetically accordingly so as to let students keep the balance between experiencing success for achievement and encountering challenge for students' mental stimulation.

\section{Make Efforts to Create a Natural Learning Environment}

Besides the qualities of the teachers, motivation in English learning process has much to do with learning environment. We can't always make a sharp distinction between natural learning and learning in the classroom. Since most Chinese students lack the natural environment, teachers should attempt to provide more communicative opportunities in the classroom for them and make the classroom environment be as similar as possible to the natural environment. Some methods are suggested here:

1. English should be used throughout the class to make students have thorough exposure to English context.

2. Provide as many opportunities as possible for students to practice English in various forms. The multiple forms include activities in whole class, in small groups or in pairs.

3. The combination of skills should be used. The combination of listening, speaking, reading, and writing is the most effective skill activity. The teaching materials are not only in print, but also audio and visual. Multi-media should be applied when the facilities are available.

\section{Cultivate the Proper Degree Sense of Anxiety}

The overall classroom socio-emotional climate created by effective teachers is one characterized as positive and productive. In other words, a harmonious and co-operative classroom atmosphere may also have a similar supportive effect. But a commonly existent phenomenon is that the LEFL classroom can easily generate situations where learners feel overanxious and constrained, and such over-anxiety is an obstacle to the learning process. Students may have difficulty relating to others and presenting themselves adequately, even the attempts to do so may result in misunderstanding and the feeling that they project silly, boring images and thus become withdrawn. For these students, the techniques that help them deal with and reduce the sense of over-anxiety include:

1. In accordance with individuals' present proficiency in English, set different standards for different students.

2. Provide tasks of immediate difficulty that are within there ach of students but still offer some challenge $n$ case they feel overburdened or over relaxed.

3. Provide easier tasks for students who are discouraged because of low or failing grades to help them regain the sense of achievement. The students' se lf-efficacy may be enhanced in this way so that they have less anxiety about their ability and show themselves bravely before the class with confidence.

4. Make them realize everyone has his advantages and disadvantages. It's quite common to receive positive or negative evaluation at different times. We should try to stimulate the classroom atmosphere to lighten students' anxiety.

\section{E. Stimulate Students' Interest in LEFL}

One of the meanings of motivation for teachers is probably the interest that generates in the students. Motivation can also take the form of intrinsic interest in learning activities and, as such, may be easily influenced by teachers. But interest is dynamic in nature. It is something that varies from one moment to the next depending on the learning context or task. It thus requires teachers to stimulate students' interest in LEFL both in class and after class. The concrete strategies are as follows:

\section{F. Strengthen Cultural Instruction in Class}

We have talked about integrative and instrumental motivations which both contribute to success above. Though instrumental motivation is the main kind among Chinese students, a sense of integration does improve students' performance in class. It's meaningful to cultivate their sense of integration through the cultural instruction of target language countries. For example, use teaching aids to make the teaching of English more effective and efficient. Teachers may collect objects and pictures which display foreign arts, customs and then show them to students. Foreign films, slides and TV programs provide cultural insights and a variety of welcome classroom activities, the regular show of which helps students know their dressing, food, housing, transportation and others more vividly.

\section{REFERENCES}

[1] Baker \&Wigfield. (1999). Dimensions of children's motivation for reading and their relations to reading activity and reading achievement. Reading Research Quarterly. 23.p78-91.

[2] Dörnyei, Z. (1998). Motivation in Second and Foreign Language Learning. Language Teaching. 31, 117-135.

[3] Domyei,Z. Otto, (1998). Motivation in action: A process model of L2 motivation. Working papers in Applied Linguistics. Thames Valley University, London.1998. 31, 117-135.

[4] Ellis, R (1998). The Study of Second Language Acquisition. Shanghai: Shanghai Foreign Language Education.

[5] Gardner \& P.D. Macintyre. (1993). A Student's Contributions to Second - language Learning: Affective Variables. Language Teaching. 78(4), 524-527.

[6] Krashen, S.D. (1982). Principles and Practice in Second Language Acquisition. New York: Pergamon Press Ltd. 
Qian Huang was born in Hangzhou, China in 1966. She received her M.A degree from Shandong University, China. She is currently an associate professor in the Department of Foreign Language Teaching, Dezhou University, Shandong, China. Her research interests include linguistics and foreign teacher's education. 